\title{
Infusion with an oxytocin receptor antagonist delays parturition in a marsupial
}

\author{
M. B. Renfree, L. J. Parry* and G. Shaw \\ Department of Zoology, The University of Melbourne, Parkville, Victoria 3052, Australia
}

\begin{abstract}
The oxytocin receptor antagonist [1-deamino-2-D-Tyr-(OEt)-4-Thr-8-Orn]-oxytocin (Atosiban) is a specific antagonist of both mesotocin- and oxytocin-induced myometrial contractions in late pregnant tammars in vitro. Continuous intravenous infusion of Atosiban ( $1 \mathrm{mg} \mathrm{kg}^{-1}$ day $^{-1}$ ) for 3 or 7 days from day 24 of the 26.5 day gestation significantly delayed births. In both the 3 day and 7 day infusion groups, all 15 control animals were pregnant and gave birth within the normal time (day $26.75 \pm 0.20$, mean \pm SEM), during the infusion of saline. The neonates weighed $387 \pm 8 \mathrm{mg}$. Deliveries were observed in 15 Atosiban-treated animals significantly $(P<0.05)$ later than in the controls (day $27.85 \pm 0.19$; neonate weight $413 \pm 9 \mathrm{mg}$ ). All pouch young were successfully suckled, even in the continued presence of Atosiban. Baseline plasma concentrations of the prostaglandin $F$ metabolite (PGFM) in pregnant tammars were $<200 \mathrm{pg} \mathrm{ml}^{-1}$. A surge in plasma PGFM occurred at birth ( $811 \pm 116 \mathrm{pg} \mathrm{ml}^{-1}$ ), followed by a rapid fall to baseline concentrations within $1 \mathrm{~h}$ after birth. This was observed both in saline- and in Atosiban-treated animals that gave birth during the observation period, and did not differ significantly between the treatment groups. Plasma progesterone concentrations in the control and the Atosibantreated animals showed the normal pattern of luteolysis immediately after birth. Thus, infusion of an oxytocin receptor antagonist at the end of gestation delays birth, the peripartum surge in prostaglandin release, and the fall in progesterone, suggesting that mesotocin is an important part of the hormonal cascade associated with delivery in this marsupial.
\end{abstract}

\section{Introduction}

The release of oxytocin during birth is well documented in many species but its physiological role in the initiation of parturition remains controversial (Liggins and Thorburn, 1994). Oxytocin is a potent stimulator of myometrial contractions via a direct action on uterine smooth muscle, and has an indirect action on the endometrium to stimulate release of prostaglan$\operatorname{din} F_{2 a}$ (Chan and Chen, 1992). Circulating oxytocin concentrations do not increase until relatively late in labour in most species studied (reviewed in Fuchs, 1990), although small, irregular oxytocin pulses have been measured in early labour in rabbits (Fuchs and Darwood, 1980) and women (Fuchs, 1990). The role of oxytocin is therefore thought to be confined to the expulsive phase of parturition. Oxytocin receptors in the endometrium and myometrium increase in concentration before parturition in all species studied (Fuchs, 1985). Oxytocin receptor action can be blocked with a synthetic oxytocin analogue such as Atosiban, which acts as a competitive inhibitor of the action of oxytocin on the uterus and inhibits uterine contractions in women (Melin et al., 1986; Akerlund et al., 1987; Goodwin et al., 1994; Maggi et al., 1994).

*Present address: Department of Molecular Biology, IHF Institute for Hormone and Fertility Research, Grandweg 64, 22529 Hamburg, Germany.

Received 27 March 1996.
Administration of different oxytocin receptor antagonists delays the onset of delivery and prolongs labour in rats (Antonijevic et al., 1995) and guinea-pigs (Schellenberg, 1995).

In marsupials the function of oxytocic peptides appears similar to that in eutherian mammals. Marsupials can produce either oxytocin, or the closely related peptide, mesotocin (8-lle-oxytocin), or both. The tammar produces only mesotocin (Chauvet et al., 1981). Oxytocin (mesotocin) receptors are present in the uteri, median vaginal sacs and mammary glands of ovariectomized, oestrogen-treated brushtail possums (Sernia et al., 1991). Myometrial activity in vivo and in vitro can be stimulated by oxytocin in the tammar (Renfree and Young, 1979; Shaw, 1983). The non-gravid uterus of late pregnant animals (from day $20 \mathrm{RPY}$ ) and both the gravid and the non-gravid uteri during lactational quiescence do not respond to exogenous oxytocin, but in late pregnancy the gravid uterus has increased contractility and sensitivity to oxytocin (Shaw, 1983; Tyndale-Biscoe and Renfree, 1987). By 1 day after birth, both uteri are refractory to oxytocin. Similarly in the quokka, Setonix brachyurus, the uterus is most sensitive to oxytocin in late pregnancy (Heller, 1974). Exogenous oxytocin induces milk ejection in marsupials (Griffiths et al., 1972), as does electrical stimulation of the presumptive mesotocinergic neurones in the hypothalamus (Lincoln and Renfree, 1981a). 
As in eutherians, there are several key hormones that interact in the control of parturition in marsupials. In the tammar, there is a surge of prostaglandin metabolite (PGFM) in plasma at birth (Lewis et al., 1986; Fletcher et al., 1990), and if prostaglandin synthesis is inhibited it prevents normal parturition (Renfree et al., 1994). A pulse of prolactin occurs before birth in pregnant tammars, but tammars can give birth without prolactin if prostaglandins are present (Fletcher et al., 1990). Plasma concentrations of progesterone are usually between 500 and $1000 \mathrm{pg} \mathrm{ml}^{-1}$ in late gestation, and fall sharply at birth (Hinds and Tyndale-Biscoe, 1982; Tyndale-Biscoe et al., 1983; Lewis et al., 1986; Fletcher et al, 1990; Renfree et al., 1994; Shaw et al., 1996), but progesterone withdrawal is not essential for parturition (Ward and Renfree, 1984). Pregnancy after early gestation is independent of the corpus luteum and goes to term after lutectomy, but birth is inhibited (Young and Renfree, 1979). Oestrus normally occurs $1-3 \mathrm{~h}$ after birth (Rudd, 1994), but postpartum oestrus is not needed for birth, so the oestrogen:progesterone ratio is unimportant (Shaw and Renfree, 1984). The fetus has an influence on the timing of birth (Tyndale-Biscoe et al., 1983) which appears to be mediated by cortisol of fetal adrenal origin, because premature delivery can be induced by exogenous glucocorticoids (Shaw et al., 1996).

Several studies also show that the maternal pituitary gland is essential for delivery of live young in tammar wallabies (Hearn, 1973). Hypophysectomy in the pregnant tammar wallaby has no effect on the normal course of pregnancy nor on the function of the corpus luteum, but parturition does not occur. Fetuses are carried to term but are found dead in the uterus at autopsy (Hearn, 1973; Hearn, 1974). Similar results have been shown in the brushtail possum (Hinds, 1990). The essential pituitary factor is not gonadotrophin (Short et al, 1985) or prolactin (Fletcher et al., 1990) as their absence does not interfere with birth. Since removal of the anterior pituitary leaving the neurohypophysis intact did not prevent evacuation of the uterus (Hearn, 1972; Hinds, 1990), it is likely that the oxytocic peptide mesotocin or another posterior pituitary hormone is required for delivery. Mesotocin concentrations are significantly increased at parturition in the tammar and decrease rapidly after birth (Parry et al., in press a), mirroring the prostaglandin pulse and its subsequent decline (Lewis et al., 1986; Fletcher et al., 1990; Renfree et al., 1994; Shaw et al., 1996).

This study investigates the influence of infusion of a specific oxytocin receptor antagonist, Atosiban ([1-deamino-2-D-Tyr(OEt)-4-Thr-8-Orn]-oxytocin), on parturition in the tammar wallaby.

\section{Materials and Methods}

\section{Animals}

Adult female tammar wallabies were obtained from the wild on Kangaroo Island, South Australia and maintained in our captive breeding colony established at Clayton, Victoria. They were housed with males in open grassy enclosures, and lucerne hay, oats and water were freely available. Husbandry and handling were as described by Renfree and Tyndale-Biscoe (1978). Pregnancies were synchronized in groups of tammars early in the breeding season by removing the pouch young (RPY). The females were in lactational quiescence and presumed to be carrying blastocysts in lactational diapause. Removal of the pouch young (RPY) terminates lactational diapause and the quiescent blastocyst resumes development, with births expected 26.4 \pm 0.2 days later (Renfree et al., 1989). The day of RPY was designated day 0 of pregnancy. Animals were divided into two experimental groups. In the first experiment, infusions were made for 3 days; in the second, for 7 days.

Care and treatment of the animals conformed to the National Health and Medical Research Council of Australia/ Commonwealth Scientific and Industrial Research Organisation/Australian Research Council 1990 guidelines "Australian code of practice for the care and use of animals for scientific purposes" and all experiments were approved by Institutional Animal Experimentation Ethics Committees.

\section{Implantation of minipumps}

Osmotic minipumps (Alzet Corporation, Palo Alto, CA) were surgically implanted 2 days before expected births (day 24 of pregnancy). Surgery at this stage of pregnancy does not interfere with the timing of parturition in this species (Renfree and Tyndale-Biscoe, 1978; Young and Renfree, 1979). Anaesthesia was induced with intravenous pentobarbitone sodium (60 $\mathrm{mg} \mathrm{ml}^{-1}$ ) (Abbott Laboratories, Kurnell, NSW) administered to effect via a lateral tail vein. Under sterile surgical conditions, the external jugular vein was cannulated with silastic tubing (Dow Corning, Midland, MI). The free end of the cannula was attached to the flow moderator of the minipump which was tunnelled to a pocket under the ventral neck skin. The incision was dusted with antibiotic powder (Tricin: V.R. Laboratories (Aust.) Pty Ltd, Thornleigh, NSW) and sutured. Each animal was given an intramuscular injection of antibiotic (Duplocillin: Kelta Enterprises, Pascoe Vale, Victoria, Australia) and was returned to a small grassed enclosure for observation. At the end of the experiment, one week later, the incision was re-opened, the cannula and minipump were both removed, and the jugular vein was ligated. Careful note was made whether the cannula was still attached to the minipump. All the animals recovered completely from this surgery with no evidence of internal haemorrhaging or tissue necrosis.

\section{Effects of Atosiban in vitro}

Preliminary experiments were performed to confirm that the designated oxytocin receptor antagonist Atosiban blocked the action of exogenous mesotocin in tammars. Like all marsupials, tammars have two completely separate uteri with separate cervices. The tammar is monovular so there is always an independent gravid and non-gravid uterus in the same animal. The effects of the oxytocin receptor antagonist [1-deamino-2D-Tyr-(OEt)-4-Thr-8-Orn]-oxytocin (Atosiban, a gift from P. Melin, Ferring Research Institute, Malmö) on mesotocininduced contractions of tammar uteri were tested in vitro. Longitudinal strips of myometrium were removed from the gravid uterus of pregnant tammars at days II $(n=2), 19(2), 23$ 
(2), 24 (2), 25 (1), and 26 (3) of pregnancy and one tammar $72 \mathrm{~h}$ after birth. Strips were suspended in an organ bath containing $10 \mathrm{ml} \mathrm{Krebs-Ringer} \mathrm{solution} \mathrm{at} 37^{\circ} \mathrm{C}$, gassed with $95 \% \mathrm{O}_{2}: 5 \%$ $\mathrm{CO}_{2}$, and isometric contractions were measured on a Grass transducer attached to MacLab data logging equipment. The effects of different doses of mesotocin $\left(0.1-10 \mathrm{ng} \mathrm{ml}^{-1}\right)$ and oxytocin $\left(1-10 \mathrm{mU} \mathrm{ml}^{-1}\right.$ ), on myometrial contractions were tested before and after treatment with 0.1 or $0.5 \mu \mathrm{g}$ Atosiban $\mathrm{ml}^{-1}$. Specificity of the antagonist was tested with a prostaglandin (PG) $\mathrm{F}_{2 u}$ analogue, cloprostenol $\left(0.5-5.0 \mathrm{ng} \mathrm{ml}^{-1}\right.$ ).

\section{Effects of Atosiban in vivo}

Dose rates were based on advice kindly provided by $\mathrm{P}$. Melin. Two experiments were conducted: Atosiban and control infused animals were all treated at the same time within each experiment, in the middle of the breeding season (March) to avoid any potential seasonal bias in the timing or births. For 3 day infusions, 20 animals were implanted two days before expected births (day 24) with osmotic minipumps (Alzet $1003 \mathrm{D}, 1.0 \mu \mathrm{h} \mathrm{h}^{-1}$ ) to infuse via the jugular vein, either saline (controls, $n=8$ ) or the oxytocin receptor antagonist (Atosiban $1 \mathrm{mg} \mathrm{kg}{ }^{-1}$ day $^{-1}: n=12$ ) for 3 days. Similarly, for 7 day infusions, 17 animals were implanted on day 24, with osmotic minipumps (Alzet 2001, $1.0 \mu \mathrm{h} \mathrm{h}^{-1}$ ) to infuse via the jugular vein, either saline (controls, $n=8$ ) or Atosiban $(n=9)$ for 7 days. After surgery, the animals were placed in observation pens and from 08:00 h on day 25, and watched continuously for birth. Blood samples $(2.5 \mathrm{ml})$ were taken from a tail vein catheter inserted at 08:00 h on day 25 (Renfree et al., 1994) at $8 \mathrm{~h}$ intervals until birth was observed. Time of birth was recorded as the moment the neonate emerged from the urogenital opening. After birth, a sample was taken as soon as the young entered the pouch (mean time of sample $10 \mathrm{~min}$ after birth). After birth blood samples were taken at $20 \mathrm{~min}$, $40 \mathrm{~min}, 1 \mathrm{~h}, 2 \mathrm{~h}, 4 \mathrm{~h}, 6 \mathrm{~h}, 8 \mathrm{~h}, 12 \mathrm{~h}, 16 \mathrm{~h}$ and $24 \mathrm{~h}$. Sample volume varied between 1.5 and $5 \mathrm{ml}$ depending on which hormones were to be assayed at each point. All blood was collected into heparinized syringes, centrifuged at $1700 \mathrm{~g}$ for 15 min and plasma stored at $-20^{\circ} \mathrm{C}$ until assayed for PGFM and progesterone. Immediately after birth, but before attachment to the teat, the neonatal young were weighed, and the head length was measured. They were then placed close to the teats to which they attached within $2 \mathrm{~min}$. The neonates were removed again $24 \mathrm{~h}$ after birth, weighed and replaced within the pouch or directly on the teat. Pouch young were checked for reattachment at each blood sampling period, and mothers checked for the presence of a copulatory plug.

Non-parturient animals were examined by laparotomy on day 28 to assess their reproductive status and diagnosed as pregnant (post partum) or not pregnant based upon the appearance of the uteri (Ward and Renfree, 1984).

\section{Progesterone assay}

Progesterone was measured in $200 \mu \mathrm{l}$ aliquots of plasma by the method of Renfree et al. (1994) for tammar plasma, using antiserum S9817. The sensitivity of the assay was $20 \mathrm{pg}$ progesterone per tube. The interassay coefficient of variation
(CV) was $16.9 \%$ and the intra-assay $\mathrm{CV}$ was $8.2 \%(n=4$ assays). Solvent and buffer blanks included in every assay were consistently below the sensitivity of the assay.

\section{PGFM assay}

PGFM (13,14-dihydro-15-keto-prostaglandin- $\left.\mathrm{F}_{2 u}\right)$ was measured in $100 \mu \mathrm{l}$ aliquots by the method of Lewis et al. (1986). Sensitivity of the assay was $15.6 \mathrm{pg}$ PGFM per tube. The inter-assay $\mathrm{CV}$ was $15.4 \%$ and the intra-assay $\mathrm{CV}$ was $3.4 \%(n=3$ assays).

\section{Statistical analyses}

Differences between groups in time of parturition and neonatal weight and hormone concentrations were assessed by analysis of variance, with between-group differences determined by the Tukey-Kramer multiple range test. Animals in which the minipump was detached from the intravenous catheter at surgery were treated as a separate group for statistical analysis. Progesterone profile data were analysed by repeated measures analysis of variance. Variations in timing of birth meant that pre-birth samples were not synchronized between animals, so data for the repeated measures analysis were averages within each animal in the following time groups: $88-33 \mathrm{~h}, 32-16 \mathrm{~h}, 8-4 \mathrm{~h}$ before birth, and $40 \mathrm{~min}$, and I, 2, 4 and $8-16 \mathrm{~h}$ after birth. Statistical tests were performed using the SAS statistical package (SAS, 1985).

\section{Results}

\section{Effects of Atosiban on the myometrium in vitro}

Both mesotocin and oxytocin induced dose-dependent increases in basal tone, amplitude and frequency of myometrial contractions at all stages tested, although, as in previous studies, the uterine responsiveness was lower at day 10-11 than at later stages of pregnancy (data not shown). Pretreatment with Atosiban had no effect on the spontaneous contractions that were observed in about half the strips, but it substantially reduced the uterine contractions induced by mesotocin and oxytocin (Fig. 1). In some strips 0.1 g Atosiban $\mathrm{ml}^{-1}$ was inadequate to block the effects of 7-10 ng mesotocin $\mathrm{ml}^{-1}$. The effect of Atosiban was reversible, since after washing mesotocin or oxytocin could again stimulate strong contractions (Fig. 1). Atosiban had no effect on $\mathrm{PGF}_{2 u}$-induced myometrial contractions.

\section{Effects of Atosiban on parturition}

In 3 day infusions, all seven control animals gave birth within the normal time, on day $26.62 \pm 0.22$ (mean \pm SEM) (Fig. 2). The neonates weighed $394 \pm 14 \mathrm{mg}$ (Fig. 3). Nine Atosibantreated animals delivered live young significantly $(P<0.05)$ later, on day $27.91 \pm 0.23$ (neonate weight $416.25 \pm 12.25 \mathrm{mg}$ ) (Fig. 3). A tenth Atosiban-treated animal was pregnant at laparotomy late on day 28; a live young was observed in her pouch 4 days later (day 32), but the exact time of birth and weight of neonate were not known. This animal was not used 

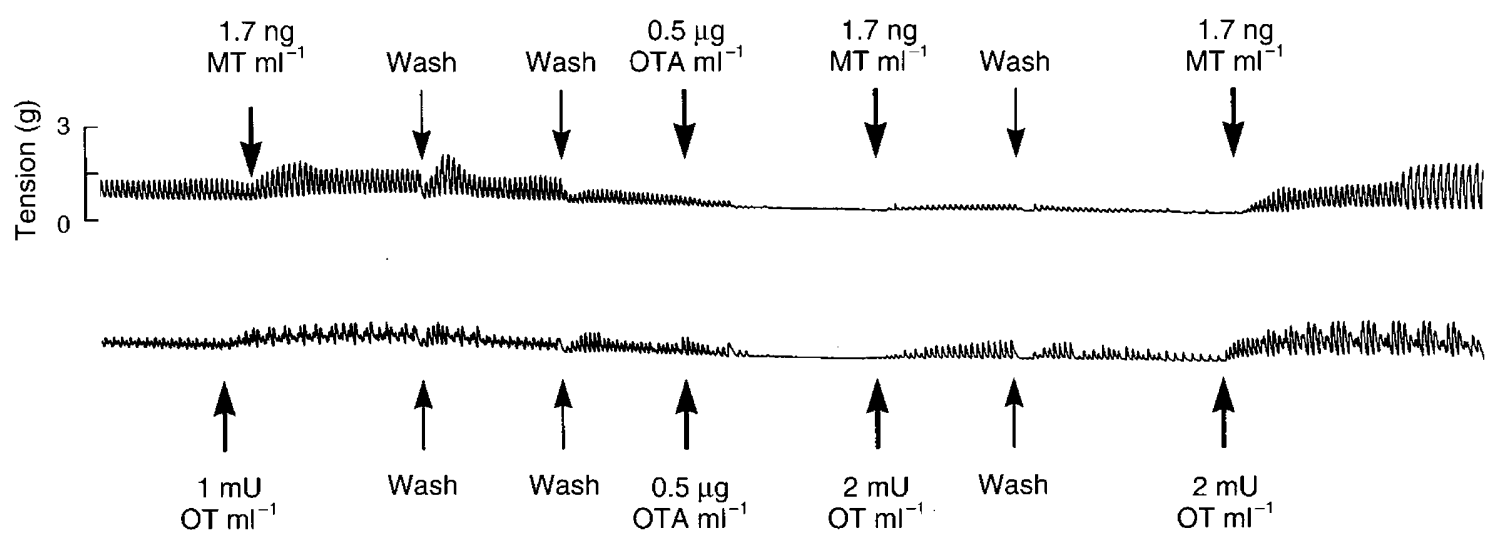

Fig. 1. A representative tracing showing contractions of strips of myometrium of a tammar on day 26 of pregnancy in vitro. Contractions induced by oxytocin (OT) and mesotocin (MT) are blocked by the oxytocin receptor antagonist Atosiban (OTA). This inhibition is reversed by washing.

in the statistical analyses. An eleventh Atosiban-treated animal gave birth 26.21 days after RPY, but the minipump was detached from the intravenous catheter. The remaining two animals were not pregnant at laparotomy on day 28 .

Since delivery occurred at about the end of the 3 day infusion in these animals, a second experiment was conducted with a 7 day infusion to determine whether parturition could be further delayed. In 7 day infusions, all eight control animals gave birth within the normal time, on day $26.87 \pm 0.33$ (neonate weight $380 \pm 9 \mathrm{mg}$ ) (Fig. 3). Three Atosiban-treated animals had catheters detached from the minipump when these were removed, and these gave birth on day $26.59 \pm 0.17$, not significantly different from controls $(P>0.10)$. Six Atosibantreated animals delivered live young during the infusion but significantly $(P<0.05)$ later than did the controls, on day $28.22 \pm 0.27$ (neonate weight $407 \pm 16 \mathrm{mg}$ ) (Fig. 2). There was no significant difference between the 3 day and 7 day infusion groups in time of birth or neonatal weight $(P>0.2)$. Although pouch young weights at birth or at $24 \mathrm{~h}$ did not differ between groups $(P>0.2)$, there was a significant increase in weight between birth and $24 \mathrm{~h}$ in all groups $(P<0.05)$ (Fig. 3).

(a)

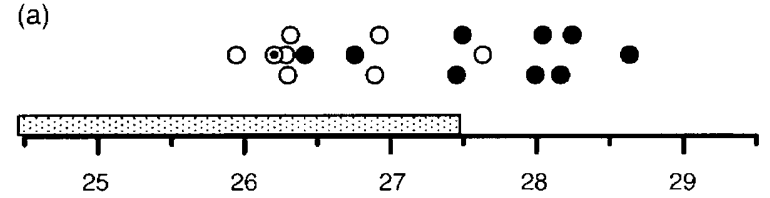

(b)

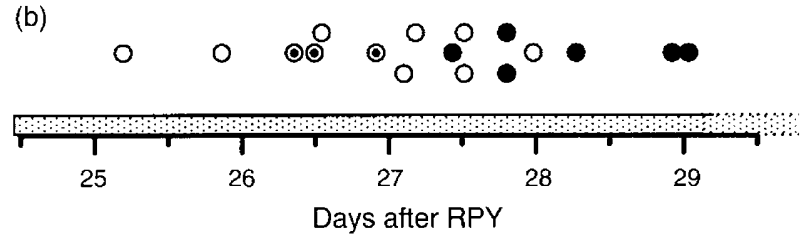

Fig. 2. Timing of parturition in tammars after intravenous infusion with Atosiban ( or saline (O) for 3 (a) or 7 (b) days. Birth normally occurs 26.5 days after removal of pouch young (RPY). Animals with detached catheters $(\Theta)$ were not significantly different from those of the control groups, but Atosiban infusion significantly delayed births. The stippled bars indicate the duration of infusion.

\section{Hormonal profiles at parturition}

At the time of birth the patterns of change of plasma progesterone and PGFM of treated and control animals were similar. A surge in plasma PGFM occurred at birth (peak concentrations $811 \pm 106 \mathrm{pg} \mathrm{ml}^{-1}$ ), followed by a rapid fall, both in saline and in Atosiban-treated tammars (Fig. 4) that gave birth during the observation period. However, since the PGFM surge in Atosiban-treated animals was coincident with birth, it was delayed relative to the day after RPY compared with that in controls $(27.94 \pm 0.19$ days versus $26.75 \pm 0.20$ days). In both control and Atosiban-treated females, plasma progesterone was high before birth and then fell precipitously at parturition (Fig. 4). Atosiban-treated animals had significantly lower progesterone concentrations $\left(544 \pm 21 \mathrm{pg} \mathrm{ml}^{-1}\right.$ )

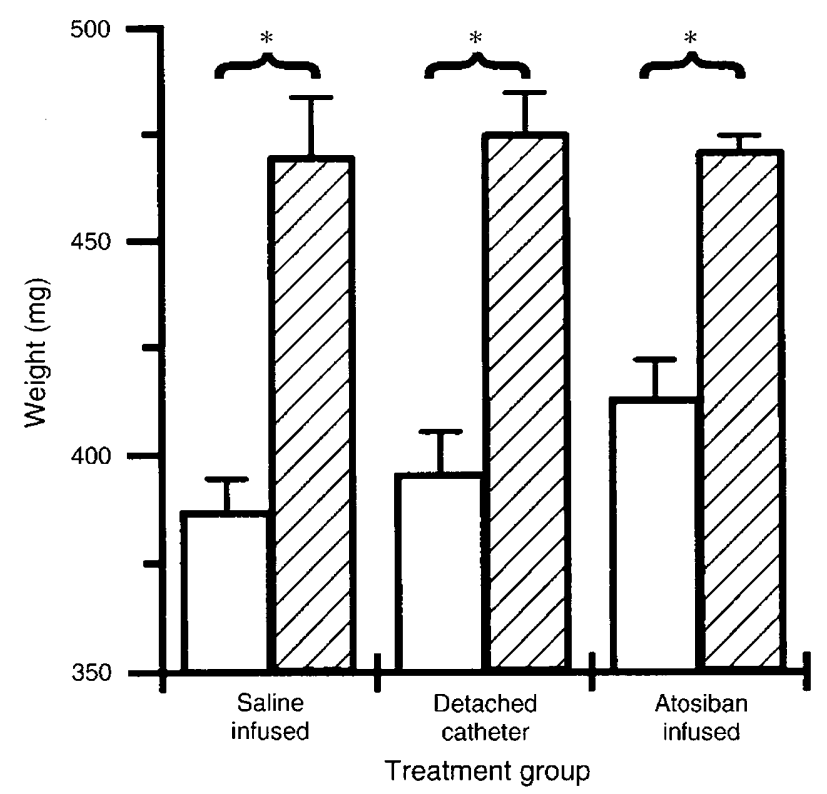

Fig. 3. Weights (mean \pm SEM) of pouch young at birth $(\square)$ and after $24 \mathrm{~h}(\mathbb{Z})$ in control tammars $(n=15)$, Atosiban-treated tammars with detached catheters $(n=4)$ or Atosiban-treated $(n=15)$. Weights do not differ significantly either at birth or after $24 \mathrm{~h}$ sucking, but all groups had a significant weight gain $\left(^{*}\right)$ after $24 \mathrm{~h}$. 

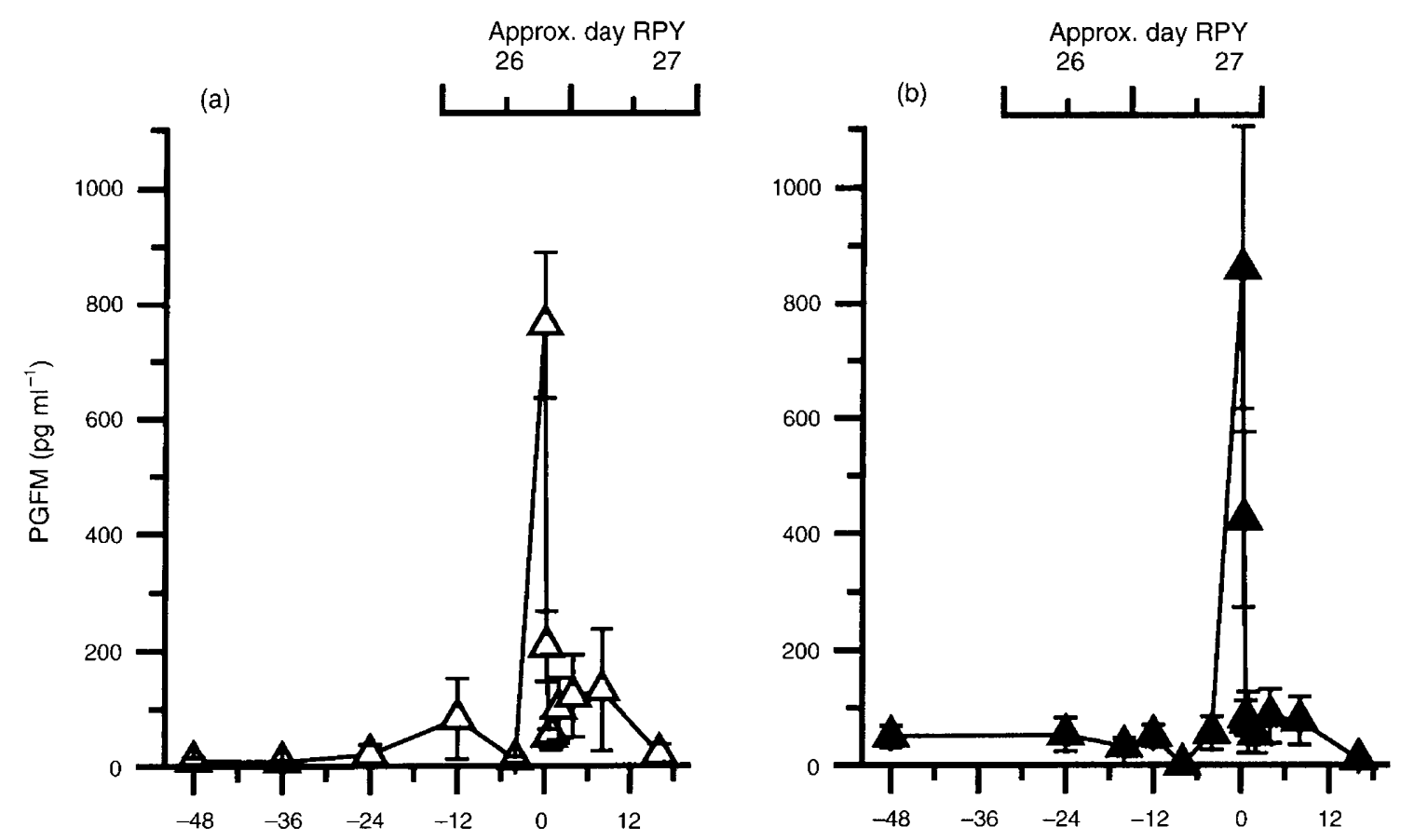

(c)

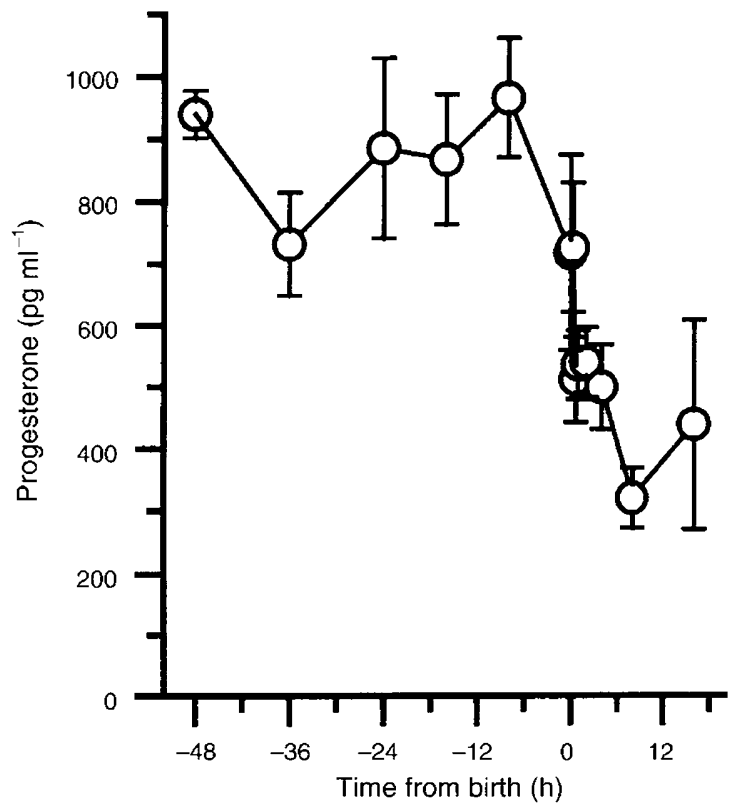

(d)

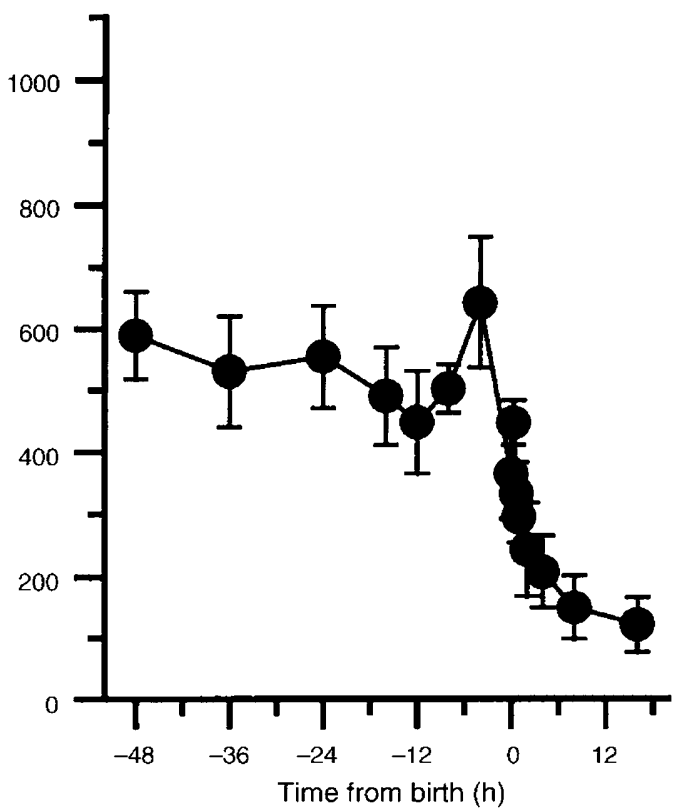

Fig. 4. Profiles of prostaglandin $(\Delta, \mathbf{\Delta})$ and progesterone $(\mathrm{O}, \mathbf{O})$ in the peripheral plasma of control (a, $c$, open symbols) and Atosiban-treated ( $b$,d, solid symbols) tammars infused for 3 or 7 days (combined data; animal numbers as in Figs 2 and 3). Inset shows average time after removing pouch young (RPY). In controls birth occurred at $26.75 \pm 0.2$ days after RPY, within the normal range. With Atosiban infusion, birth occurred at $27.90 \pm 0.19$ days after RPY, significantly later than in control animals.

than did controls $\left(833 \pm 40 \mathrm{pg} \mathrm{ml}^{-1}\right)$ before birth (averaged pre-birth samples) (Fig. 4). The differences in these concentrations were evident before treatment started, and are within the normal range of between-animal variation (Hinds and Tyndale-Biscoe, 1982; Lewis et al., 1986; Fletcher et al., 1990; Renfree et al., 1994; Shaw et al., 1996). Using repeated measures analysis of variance there was no significant effect of treatment (Atosiban or control; 3 day or 7 day infusion) on the profile of progesterone secretion around parturition when pretreatment progesterone concentrations were used as a covariate $(P>0.1)$. There was a significant effect of time within animals $(P<0.001)$ owing to the rapid fall of progesterone after parturition. 


\section{Discussion}

Atosiban specifically inhibits mesotocin-induced contractions of the tammar uterus, and infusion of Atosiban in late gestation delays but does not prevent birth. This provides evidence that mesotocin action is important for parturition in this marsupial.

The lack of effect of Atosiban in the animals with detached catheters suggests that intravenous infusion of this drug is needed for full potency. Similar results have been observed in sheep, in which intravenous but not subcutaneous infusion of Atosiban into cyclic sheep prevented luteolysis (G. Jenkin, personal communication).

There are many parallels in the control of parturition between wallabies and eutherians such as rats and sheep and even horses (Renfree, 1994; Liggins and Thorburn, 1994). In all these species PG is essential for birth, and there is a rapid rise of PG release in labour. In these eutherians oxytocin concentrations rise at birth. Similarly, in the tammar plasma PG and mesotocin concentrations rise sharply from undetectable to about $1 \mathrm{ng} \mathrm{ml}^{-1}$ (PGFM) and to about $500 \mathrm{pg} \mathrm{ml}^{-1}$ (mesotocin) at birth, and then fall to less than $200 \mathrm{pg} \mathrm{ml}^{-1}$ (PGFM) and $100 \mathrm{pg} \mathrm{ml}^{-1}$ (mesotocin) within $40 \mathrm{~min}$ after birth (Lewis et al., 1986; Fletcher et al., 1990; Renfree et al., 1994; Parry et al., in press a). Since birth occurred significantly later in tammars treated with the oxytocin-receptor inhibitor (this study), mesotocin is clearly important for normal parturition in this marsupial. In rats there are conflicting data about the relative importance of PGs and oxytocin, and unlike in the wallaby, parturition in rats needs a change in the oestradiol:progesterone ratio. Chan and Chen (1992) concluded that functional oxytocin receptors are not essential for the initiation of labour, but play a facilitatory role in parturition, subservient to prostaglandin. As in the wallaby (Renfree et al., 1994), suppression of PG synthesis during labour in rats resulted in prolongation or failure of parturition. In rats, there are two receptor subtypes, one which has uterotonic and the other PG-releasing actions (Chan et al., 1993), and blocking the uterotonic receptor alone prolongs parturition but does not delay the onset of labour. In contrast, a single dose of two other oxytocin antagonists (OVT16 and F382) delayed the initiation of parturition in rats, and also prolonged its active phase (Antonijevic et al., 1995). In guinea-pigs (Schellenberg, 1995), the onset of the expulsive phase of labour was also delayed but not prevented by an oxytocin antagonist (F372).

The myometrium of the tammar is sensitive to both oxytocin (Renfree and Young 1979, Shaw, 1983, Young, 1979) and mesotocin (this study) in later stages of pregnancy. In vitro it contracted in response to these two peptides. Whilst Atosiban inhibited oxytocin and mesotocin-induced myometrial contractility, it had no effect on contractions induced by $\mathrm{PGF}_{2 a}$. Thus, birth could be expected in the presence of a sufficient prostaglandin stimulus even if mesotocin-induced contractility was reduced by Atosiban. The endometrium and the yolk sac placenta of tammars synthesise increasing amounts of prostaglandin near term (Shaw et al., 1995a, b; Bell and Shaw, 1995). It is likely that there is a positive feedback loop between mesotocin, PGs and uterine contractions as in other mammals (Liggins and Thorburn, 1994). Oxytocin receptors in the uterus increase before parturition in eutherians in response to prostaglandins (Fuchs, 1985), and we have evidence that mesotocin receptors increase in the tammar myometrium (Parry et al., in press). The delay in the PG pulse and birth may represent the additional time necessary to build up PG concentrations in the continued presence of the mesotocin receptor antagonist Atosiban. Alternatively, the delay may be due to a need to reach a threshold concentration of mesotocin to displace Atosiban from the receptor, allowing (delayed) birth.

The hypothesis that sufficient mesotocin can displace the agonist gains some support from receptor binding studies. Competitive binding studies using wallaby myometrial membrane preparations suggest that Atosiban is not a very potent inhibitor, needing about a 100 -fold excess to displace $50 \%$ of our tritiated oxytocin standard (L. Sebastian, M. B. Renfree and G. Shaw, unpublished) or iodinated standard (Parry et al., in press b). A higher dose may have completely blocked delivery.

Oxytocin injection stimulates milk ejection in marsupials and monotremes (Griffiths et al., 1972; Griffiths, 1978). In the agile wallaby, Macropus agilis, intra-ductal mammary pressure rises in response to oxytocin injection, and to electrical stimulation of the presumptive mesotocinergic neurones in the brain (Lincoln and Renfree, 1981a, b). The mammary gland in early, but not late, lactation has an exquisitely sensitive response to oxytocin, suggesting that this may be due to a change in receptor concentration during lactation (Renfree, 1983). This idea is supported by the high concentration of oxytocin receptors in small mammary glands of another marsupial, the possum, which decrease with growth of the gland (Sernia et al., 1991). Despite the presence of Atosiban, the neonatal young in our study were successfully suckled and put on weight within $24 \mathrm{~h}$ of birth, even in the 7 day infusions which would have continued to release Atosiban up to day 31 (see Figs 2 and 3). This further suggests that inhibition of the mesotocin receptors by Atosiban was not complete, and that the inhibitor is readily displaced by high circulating mesotocin as occurs during each sucking episode. However, further studies are needed to establish whether mesotocin is essential for milk ejection, because lactation can continue and small pouch young can grow even after denervation of the mammary gland (Renfree, 1979).

Thus, infusion of the oxytocin receptor antagonist Atosiban at the end of gestation does not appear to affect the nature of the peripartum surge in prostaglandin release or the fall in progesterone, but does delay the time of delivery and the related hormonal events. The marked hormonal changes that occur at birth indicate that prostaglandin, progesterone and mesotocin are all part of a coordinated system linked to birth. Characterization of prostaglandin and mesotocin receptors may clarify their relative roles in this process.

We are especially grateful to P. Melin and Ferring Pharmaceuticals for the generous gift of the oxytocin antagonist Atosiban. We thank A. Duns and R. Moyle for their assistance with the animal observations and the collection of blood samples and G. Jenkin for helpful suggestions concerning dose rates and treatment. R. I. Cox (CSIRO, Division of Animal Production, Blacktown, NSW) provided progesterone antiserum. A. P. F. Flint (Department of Physiology, University of Nottingham) kindly provided PGFM antiserum. Animals were held under permit number RP-92-099 from the Department of Conservation and Natural Resources, Victoria, Australia. This research received funding from the Australian Research Council. 


\section{References}

Ákerlund M, Stromberg P, Hauksson A, Andersen LF, Lyndrup J, Troinar J and Melin P (1987) Inhibition of uterine contractions of premature labour with an oxytocin analogue: results from a pilot study British Journal of Obstetrics and Gynecology 94 1041-1044

Antonijevic IA, Douglas AJ, Dye S, Bicknell RJ, Leng G and Russell JA (1995) Oxytocin antagonists delay the initiation of parturition and prolong its active phase in rats Journal of Endocrinology 145 97-103

Bell, EC and Shaw, G (1995) Prostaglandin-E2 synthesis by placental tissue during late pregnancy in the tammar wallaby, Macropus eugenii Biology of Reproduction Supplement $\mathbf{5 2} 528$

Chan WY and Chen D (1992) Myometrial oxytocin receptors and prostaglandin in the parturition process in the rat Biology of Reproduction 46 58-64

Chan WY, Chen DL and Manning M (1993) Oxytocin receptor subtypes in the pregnant rat myometrium and decidua: pharmacological differentiations Endocrinology 132 1381-1386

Chauvet MT, Hurpet D, Chauvet J and Acher R (19981) A reptilian neurohypophysial hormone, mesotocin (lle ${ }^{8}$-oxytocin), in Australian marsupials FEBS Letters 129 120-122

Fletcher TP, Shaw G and Renfree MB (1990) Effects of bromocriptine at parturition in the tammar wallaby, Macropus engenii Reproduction, Fertility and Development 2 79-88

Fuchs AR (1985) Oxytocin in animal parturition. In Oxytocin, Clinical and Laboratory Studies pp 207-235 Eds JA Amico and AG Robinson. Elsevier Science Publishers, Amsterdam

Fuchs AR (1990) Oxytocin and oxytocin receptors: maternal signals for parturition. In Uterine Contractility: Mechanisms of Control pp 177-190 Ed. RE Garfield. Serono Symposia, Norwell

Fuchs AR and Darwood MY (1980) Oxytocin release and uterine activation during parturition in rabbits Endocrinology 107 1117-1126

Goodwin TM, Paul R, Silver H, Spellacy W, Parsons M, Chez R, Hayashi R, Valenzuela G. Creasy GW and Merriman R (1994) The effect of the oxytocin antagonist Atosiban on preterm uterine activity in the human American Journal of Obstetrics and Gynecology $170474-478$

Griffiths ME (1978) The Biology of the Monotremes Academic Press, New York

Griffiths ME, McIntosh DL and Leckie RM (1972) The mammary glands of the red kangaroo, with observations on the fatty acid components of the milk triglycerides Journal of Zoology London 166 265-275

Hearn JP (1972) The Pituitary Gland and Reproduction in the Marsupial, Macropus eugenii (Desmarest) PhD Thesis, Australian National University, Canberra.

Hearn JP (1973) Pituitary inhibition of pregnancy Nature 241 207-208

Hearn JP (1974) The pituitary gland and implantation in the tammar wallaby, Macropus engenii Journal of Reproduction and Ferfility 42 399-402

Heller H (1974) Molecular aspects in comparative endocrinology General and Comparative Endocrinology 22 315-332

Hinds LA (1990) Control of pregnancy, parturition and luteolysis in marsupials Reproduction. Fertility and Development 2 535-552

Hinds LA and Tyndale-Biscoe $\mathrm{CH}$ (1982) Plasma progesterone levels in the pregnant and non-pregnant tammar, Macropus eugenii Journal of Endocrinology $9399-107$

Lewis PR, Fletcher TP and Renfree MB (1986) Prostaglandin in the peripheral plasma of tammar wallabies during parturition Journal of Endocrinology 111 103-109

Liggins GC and Thorburn GD (1994) Initiation of parturition. In Marshall's Physiology of Reproduction Vol. 3 Part 2 (4th edn) pp 863-1021 Ed. GE Lamming. Chapman and Hall, London

Lincoln DW and Renfree MB (1981a) Mammary gland growth and milk ejection in the agile wallaby. Macropus agilis, displaying concurrent asynchronous lactation Journal of Reproduction and Fertility 63 193-203

Lincoln DW and Renfree MB (1981b) Milk ejection in a marsupial Macropus agilis Nature 289 504-506

Maggi M, Fantoni G, Baldi E, Cioni A, Rossi S, Vannelli GB, Melin P, Ákerlund M and Serio $M$ (1994) Antagonists for the human oxytocin receptor: an in vitro study Journal of Reproduction and Fertility $101345-352$

Melin P, Trojnar J, Johansson B, Vilhardt H and Åkerlund M. (1986) Synthetic antagonists of the myometrial response to vasopressin and oxytocin Journal of Endocrinology 111 125-131
Parry LJ, Guymer F, Fletcher TP and Renfree MB (1996) Release of an oxytocic peptide at parturition in a marsupial Journal of Reproduction and Fertility (in press a)

Parry LJ, Bathgate RAD, Shaw G, Renfree MB and Ivell R Differential regulation of uterine oxytocic receptors during pregnancy in a marsupial Biology of Reproduction (in press b)

Renfree MB (1979) Initiation of development of diapausing embryo by mammary denervation during lactation in a marsupial Nature 278 549-551

Renfree MB (1983) Marsupial reproduction: the choice between placentation and lactation Oxford Reviews of Reproductive Biology 5 1-29.

Renfree MB (1994) Endocrinology of pregnancy, parturition and lactation of marsupials. In Marshall's Physiology of Reproduction Vol. 3 Part 2 (4th edn) pp 677-766 Ed. GE Lamming. Chapman and Hall, London

Renfree MB and Tyndale-Biscoe CH (1978) Manipulation of marsupial embryos and pouch young. In Methods of Mammalian Reproduction pp 307-331 Ed. JC Daniel. Academic Press, London.

Renfree MB and Young IR (1979) Steroids in pregnancy and parturition in the marsupial, Macropus eugenii journal of Steroid Biochemistry 11 515-522

Renfree MB, Fletcher TP, Blanden DR, Lewis PR, Shaw G, Gordon K, Short RV, Parer-Cook E and Parer D (1989) Physiological and behavioural events around the time of birth in macropodid marsupials. In Kangaroos, Wallabies and Rat Kangaroos pp 323-337 Eds G Grigg, P Jarman and ID Hume. Surrey Beatty \& Sons Pty Ltd, Sydney

Renfree MB, Shaw G and Fletcher TP (1994) Evidence for the essential role of prostaglandins for parturition in a marsupial, Macropus eugenii journal of Reproduction and Fertility 102 433-446

Rudd C (1994) Sexual behaviour of female and male tammar wallabies, Macropus engenii, at postpartum oestrus Journal of Zoology 232 151-162

SAS Institute Inc. (1985) SASISTAT Guide for Personal Computers, Version 6 Edition SAS Institute Inc., Carey, NC

Schellenberg J (1995) The effect of oxytocin receptor blockade on parturition in guinea pigs Journal of Clinical Investigation 95 13-19

Sernia C, Thomas WG and Gemmell RT (1991) Oxytocin receptors in the mammary gland and reproductive tract of a marsupial, the brushtail possum (Trichosurus vulpecula) Biology of Reproduction 45 673-679

Shaw G (1983) Effect of PGF2 on uterine activity, and concentrations of 13,14-dihydro-15-keto-PGF2 in peripheral plasma during parturition in the tammar wallaby (Macropus engenii) Journal of Reproduction and Fertility 69 429-436

Shaw G and Renfree MB (1984) Concentrations of oestradiol-17 in plasma and corpora lutea throughout pregnancy in the tammar Macropus engenii Journal of Reproduction and Fertility $\mathbf{7 2}$ 29-37

Shaw G, Gehring H and Bell EC (1995a) Prostaglandin production by placental tissues in late pregnant tammar wallabies Proceedings of the Australian Society for Reproductive Biology 2645

Shaw G, Gehring H and Bell EC (1995b) Prostaglandin production by endometrium in late pregnant tammar wallabies Proceedings of the Australian Society for Reproductive Biology 2646

Shaw G, Renfree MB, Fletcher TP (1996) A role for glucocorticoids in parturition in a marsupial, Macropus eugenii Biology of Reproduction 54 728-733

Short RV, Flint APF and Renfree MB (1985) Influence of passive immunisation against gonadotrophin releasing hormone on pregnancy and parturition in the tammar wallaby Journal of Reproduction and Fertility 75 567-575

Tyndale-Biscoe CH and Renfree MB (1987) Reproductive Physiology of Marsupials Cambridge University Press, Cambridge

Tyndale-Biscoe CH, Hinds LA, Horn CA and Jenkin G (I983) Hormonal changes at oestrus, parturition and post-partum oestrus in the tammar wallaby (Macropus engenii) Journal of Endocrinology 96 155-161

Ward KL and Renfree MB (1984) Effects of progesterone on parturition in the tammar Macropus engenii Journal of Reproduction and Fertility 72 21-28

Young IR (1979) The Physiology of Parturition in the Macropodid, Macropus eugenii (Desmarest) PhD Thesis, Murdoch University, Western Australia

Young IR and Renfree MB (1979) The effects of corpus luteum removal during gestation on parturition in the tammar wallaby, Macropus engenii Journal of Reproduction and Fertility 56 249-254 